City University of New York (CUNY)

CUNY Academic Works

2013

\title{
TOWARD TARGET 2 OF THE GLOBAL STRATEGY FOR PLANT CONSERVATION: AN EXPERT ANALYSIS OF THE PUERTO RICAN FLORA TO VALIDATE NEW STREAMLINED METHODS FOR ASSESSING CONSERVATION STATUS
}

\author{
James S. Miller \\ New York Botanical Garden \\ Gary A. Krupnick \\ National Museum of Natural History \\ Hannah Stevens \\ New York Botanical Garden \\ Holly Porter-Morgan \\ CUNY LaGuardia Community College \\ Brian Boom \\ New York Botanical Garden
}

See next page for additional authors

\section{How does access to this work benefit you? Let us know!}

More information about this work at: https://academicworks.cuny.edu/lg_pubs/66

Discover additional works at: https://academicworks.cuny.edu

This work is made publicly available by the City University of New York (CUNY).

Contact: AcademicWorks@cuny.edu 


\section{Authors}

James S. Miller, Gary A. Krupnick, Hannah Stevens, Holly Porter-Morgan, Brian Boom, Pedro Acevedo-

Rodríguez, James Ackerman, Duane Kolterman, Eugenio Santiago, Christian Torres, and Jeanine Velez 
TOWARD TARGET 2 OF THE GLOBAL STRATEGY FOR PLANT CONSERVATION: AN EXPERT ANALYSIS OF THE PUERTO RICAN FLORA TO VALIDATE NEW STREAMLINED METHODS FOR ASSESSING CONSERVATION STATUS $^{1}$
James S. Miller, ${ }^{2}$ Gary A. Krupnick, ${ }^{3}$ Hannah Stevens, ${ }^{2}$ Holly Porter-Morgan, ${ }^{2,4}$ Brian Boom, ${ }^{2}$ Pedro Acevedo-Rodríguez, ${ }^{3}$ James Ackerman, ${ }^{5}$ Duane Kolterman, ${ }^{6}$ Eugenio Santiago, ${ }^{5,7}$ Christian Torres, ${ }^{8}$ and Jeanine Velez ${ }^{6}$

\begin{abstract}
Target 2 of the 2020 Global Strategy for Plant Conservation (GSPC) calls for a comprehensive list of the world's threatened plant species. The lack of such a list is one of the greatest impediments to protecting the full complement of the world's plant species, and work to achieve this has been slow. An efficient system for identifying those species that are at risk of extinction could help to achieve this goal in a timeframe sensitive to today's conservation needs. Two systems that efficiently use available data to assess conservation status were tested against a provisional International Union for Conservation of Nature and Natural Resources (IUCN) Red List analysis to evaluate the native seed plant species of Puerto Rico. It was demonstrated that both systems efficiently identify species at risk, which is a step toward both the GSPC Target 2 and a more comprehensive IUCN Red List for plants. Both systems were effective at identifying plant species at risk, with the New York analysis identifying $98 \%$ and the Smithsonian analysis $85 \%$ of the plant species considered Threatened in the IUCN Red List. Both analyses to some extent overestimated those plants at risk, but the species identified are all range restricted and, thus, of some conservation interest.

Key words: Global Strategy for Plant Conservation (GSPC), IUCN Red List, Puerto Rico.
\end{abstract}

Estimates of the number of flowering plant species vary widely, from about 250,000 to more than 400,000 (Stebbins, 1974; Prance et al., 2000; Govaerts, 2001; Bramwell, 2002; Miller, 2011), many with restricted ranges (Joppa et al., 2010), and perhaps more than a quarter of all flowering plants still have not been described and named (Prance et al., 2000; Miller, 2011). Furthermore, many of these species are at risk of extinction in the near future as a consequence of deforestation and habitat destruction and perhaps 94,000 species are so endangered (Pitman \& Jorgensen, 2002). There is perhaps no

${ }^{1}$ We are thankful to Robert and Encarnita Quinlan and the Prospect Hill Foundation for financial support of The New York Botanical Garden's GIS laboratory where some of these analyses were performed. We thank the University of Puerto Rico's Botanical Garden, especially Johanna Delgado, Rafael Dávila, and Eugenio Santiago, for hosting the meetings of the expert panels that led to these analyses. The Puerto Rico Department of Natural and Environmental Resources, the Fideicomiso de Conservación, and Pedro Jiménez were very supportive of these efforts. Our colleagues Alberto Areces, Frank Axelrod, and Peter Weaver contributed substantially to discussions about Puerto Rican endangered plants. We also thank the group of interns at The New York Botanical Garden, Elvio Almonte, James Fleming, Micah Gensler, Angeleta Johnson, Jubril Lawal, and Kristen MacFarlane, and at the Smithsonian Institution, Marie Balboa, John Bly, Anna Braum, Kelsey Brooks, Dana Gadeken, Matthew Johnson, Grace Liu, Holly Markley, Melissa Marshall, Eleanor Moran, Siddharth Rajagopalan, Brittany Roger, Marielle Saums, Ashley Sullivan, and Linda Yi.

${ }^{2}$ The New York Botanical Garden, 2900 Southern Blvd., Bronx, New York 10458-5126 U.S.A. jmiller@nybg.org, hannah.i.stevens@gmail.com, bboom@nybg.org.

${ }^{3}$ Department of Botany, National Museum of Natural History, Smithsonian Institution, P.O. Box 37012, Washington, D.C. 20013-7012, U.S.A. acevedop@si.edu, krupnickg@si.edu.

${ }^{4}$ LaGuardia Community College, 31-10 Thomson Ave., Room M221D, Long Island City, New York 11101, U.S.A. hporter-morgan@lagcc.cuny.edu.

${ }^{5}$ Departamento de Biología, Universidad de Puerto Rico, Recinto de Río Piedras, P.O. Box 23360, San Juan, Puerto Rico 00931-3360, U.S.A. ackerman.upr@hotmail.com.

${ }^{6}$ Departamento de Biología, Universidad de Puerto Rico, Mayagüez, Puerto Rico 00681-9012, U.S.A. dkolterman@hotmail.com, jeanine.velez@upr.edu.

${ }^{7}$ Jardín Botánico, Universidad de Puerto Rico, Apartado Postal 364984, San Juan, Puerto Rico 00936, U.S.A. esantiagoupr@gmail.com.

${ }^{8}$ International Institute of Tropical Forestry, USDA Forest Service, Jardín Botánico Sur, 1201 Calle Ceiba, San Juan, Puerto Rico 00926-1119, U.S.A. cwtorressantana@fs.fed.us.

doi: $10.3417 / 2011121$ 
greater impediment to ensuring that these threatened species persist into the future than the lack of a comprehensive list of those plant species that are at risk and most desperately need our conservation attention.

The Global Strategy for Plant Conservation (GSPC) was adopted at The Hague, The Netherlands, at the sixth meeting of the Conference of the Parties to the Convention on Biological Diversity (CBD) in 2002, establishing 16 targets under five broad aims designed to prevent the loss of plant diversity and encourage its sustainable use to improve human livelihoods (CBD, 2002). Target 1 of the GSPC was the production of "a widely accessible working list of known plant species, as a step towards a complete world flora," and Target 2 was "a preliminary assessment of the conservation status of all known plant species, at national, regional, and international levels." The GSPC was originally designed with the intention that targets would be met by 2010 , and while some progress was made on some of the targets, they were not fully accomplished, and in 2010 in Nagoya, Japan, a revised GSPC with 2020 targets was adopted (CBD, 2010). In the 2011-2020 GSPC, Target 1 was revised as "an online flora of all known plants," and the second target remained similar to the original target, being "an assessment of the conservation status of all known plant species, as far as possible, to guide conservation action" (CBD, 2011).

While the GSPC Target 2 calls for a comprehensive survey of the conservation status of all plant species, it does not identify any specific method for performing the assessments. A variety of methods are in wide use for assessing threat, including Comisión Nacional para el Conocimiento y Uso de la Biodiversidad (CONABIO's) system used to assess threat for both plants and animals in Mexico (SEMARNAT, 2002) and the system of NatureServe (<www.natureserve.org $>$ ), but the most widely used procedure has been that of the International Union for Conservation of Nature and Natural Resources (IUCN) Red List (IUCN, 2001, 2008, 2009, 2011), the only system that has been used to any significant degree globally. The Red List has been very successfully used to accomplish comprehensive assessments for amphibians (Stuart et al., 2008), birds (BirdLife International, 2008, 2013), and mammals (Schipper et al., 2008). However, collectively these vertebrate groups have fewer than 22,000 species, so completion of their conservation assessments is less daunting than it is for flowering plants, with more than 300,000 species, and to date less than 15,000 species of plants have been assessed (IUCN, 2011). Numerous Red Lists have been published, assessing the conservation status of species on a regional rather than global basis, but the only taxonomically comprehensive studies completed to date for plants are for cycads (Donaldson, 2003) and conifers (Farjon et al., 2006). The goal of the present study is to validate a streamlined system for rapid assessment of the conservation status of plant species that is complementary with the Red List procedures and to represent a first step toward accomplishing Red List analyses, but also with preliminary assessments that are useful for immediate conservation decisions.

\section{BACKGROUND}

One benefit of the IUCN Red List system is its flexibility, allowing evaluation by any one of five different criteria, depending on the type of data available, thus making it applicable to a broad range of plant and animal groups (IUCN, 2001). The IUCN Red List methods identify Threatened species and assign them to categories of Vulnerable (VU), Endangered (EN), or Critically Endangered (CR), as threat increases. Demographic data gathered over time are seldom available for plants, but the geographic range of most plant species can be determined from locality data associated with herbarium specimens with a reasonable degree of accuracy, and used to calculate Extent of Occurrence (EOO) and Area of Occupancy (AOO; Willis et al., 2003; Brummitt et al., 2008). Under the IUCN Criterion B, species are considered Threatened if their EOO or AOO values fall below specified thresholds and if they also meet two of three additional subcriteria: (a) severe fragmentation or a small number of known localities, (b) continuing decline in range, habitat, number of subpopulations, or number of individuals, or (c) extreme fluctuation in range, habitat, number of subpopulations, or number of individuals (IUCN, 2001). While both EOO and AOO can be easily calculated from locality information from herbarium specimens, there are a number of confounding issues. All of the herbarium specimens of any given species are generally distributed throughout many of the world's herbaria, rather than being together in a single institution. Furthermore, locality data from only a tiny percentage of herbarium specimens have been entered into publically available databases and only a percentage of these records are associated with geographic coordinates required for geographic information system (GIS) analysis. Rigorous and comprehensive Red List analysis using the Red List's Criterion B thus requires assembly of a great amount of specimen locality data from multiple 
herbaria and secondary efforts to georeference the records.

The less than 15,000 Red List assessments completed to date for plants are only a small step toward the GSPC 2020 Target 2, and a more efficient method than the Red List procedures could help generate the list of endangered plant species in a timeframe more sensitive to conservation needs. It seems preferable to use a streamlined procedure that would complement, rather than substitute for, the Red List system. Two systems have been developed with the aim of completing conservation assessments rapidly and efficiently, using readily available data (Miller et al., 2012), and they were tested by evaluating the global conservation status of Puerto Rican plant species and identifying those species that are At Risk. The terms "Not At Risk" and "At Risk" were specifically chosen as they do not overlap with IUCN's Red List category names and cannot be confused, but the At Risk category used here can be considered an approximation of IUCN's Threatened category, including the subcategories CR, EN, and VU. Both analyses used herbarium specimen locality data readily available in the Global Biodiversity Information Facility (GBIF) and institutional databases and did not require compilation of a set of data that was labor intensive to assemble. A detailed review of Puerto Rican native plants (Miller et al., 2012) produced provisional Red List assignments (pending their submission, approval, and acceptance by the Species Survival Program at IUCN), and results of the earlier studies were compared to validate the streamlined methods.

The flora of Puerto Rico was chosen as a test case for the proposed conservation assessment methods because it is a reasonable size, with 2009 native seed plant species (Acevedo-Rodríguez \& Strong, 2007, 2008), it is comparatively well known for a tropical flora, and it is well documented by herbarium collections. Only 53 native plant species from Puerto Rico have been identified to date as globally Threatened in the Red List (IUCN, 2011; < www. iucnredlist.org $>$ ), but this number is almost certainly an underestimate as only a small percentage $(3.9 \%$; 76 species) have been evaluated. Therefore, the flora of Puerto Rico is in serious need of assessment. It is also an appropriate size to test the validity of two streamlined methods for the conservation assessment of plant species.

\section{METHODS}

Geographic distribution information was compiled in a database hosted by The New York Botanical Garden (NY; The Puerto Rican Endangered Plants
Initiative, 2012) to provide detailed information about the range of each seed plant species native to Puerto Rico. Herbarium specimen locality records from NY and GBIF from earlier analyses were supplemented with data from the Smithsonian Institution (US) and three Puerto Rican herbaria, the University of Puerto Rico, Río Piedras (UPRRP), the Jardín Botánico of the University of Puerto Rico (UPR), and the University of Puerto Rico, Mayagüez (MAPR). Two streamlined analyses were conducted to evaluate the global conservation status of Puerto Rican seed plant species. The New York Botanical Garden's GIS lab method (NYBG-GIS) calculated the EOO from the complete herbarium specimen locality database (Miller et al., 2012). EOO was calculated for all species with at least three unique known localities by creating a minimum convex polygon using the ArcGIS extension, Hawth's tools (Beyer, 2007), the smallest polygon that encompasses all specimen localities and has no angles that exceed $180^{\circ}$ (IUCN, 2008). Areas of unsuitable habitat, such as large bodies of water, were excluded from the $\mathrm{EOO}$ calculations, using ArcGIS 9.2 (ESRI, 2007; IUCN, 2008). All species with EOO values greater than $20,000 \mathrm{~km}^{2}$ were considered to be Not At Risk. For those with calculated EOO values below $20,000 \mathrm{~km}^{2}$, collection data without geographic coordinates were retrospectively georeferenced, and EOO was recalculated. Those species with EOO values remaining below the $20,000 \mathrm{~km}^{2}$ threshold were considered At Risk. The Smithsonian method (Krupnick et al., 2009), from the Plant Conservation Unit (US-PCU), is a four-step evaluation that considers temporal, spatial, and abundance data inferred from herbarium records from US. The species is considered At Risk if all known specimens were collected before 1900, if available collections are from five or fewer localities, or if the species is known from less than the median number of specimens per species collected since 1960 from the area being evaluated.

Species identified as At Risk in both analyses were considered to be of conservation concern, and those species that were identified as At Risk by one, but not both, analyses were subjected to further review. In August 2011, an expert panel was convened at the University of Puerto Rico's Botanical Garden to test the validity of the results of the streamlined analyses. The panel was comprised of botanists from the UPRRP, MAPR, the University Botanical Garden, NY, US, the USDA's Institute for Tropical Forestry, the Department of Natural and Environmental Resources, and the Fideicomiso de Conservación de Puerto Rico. The global conservation status of each individual species was reviewed, including geographic 
range, as documented by herbarium specimens, supplemented with field observations from the experts. All species considered At Risk in either streamlined analysis were reviewed; any species considered Not At Risk in both analyses but considered to be of conservation concern by any of the experts were also included. All species provisionally assigned to one of the Red List Threatened categories under IUCN's Criterion B had an EOO less than $20,000 \mathrm{~km}^{2}$ and also met two of three subcriteria (IUCN, 2001). Thus, the primary goal of the expert panel was to evaluate those species with restricted geographic ranges for the three possible subcriteria, fragmentation, decline, or fluctuation of known populations. For each species, experts' observations on numbers of known populations, numbers of available herbarium specimens, patterns of abundance, and numbers of individuals, when known by one or more panel members, was recorded.

\section{RESUlts}

Results of the two streamlined analyses were previously reported (Miller et al., 2012), but in this review, the NY analysis was rerun with a much larger set of specimen data that recognized 2009 native seed plant species from Puerto Rico. Data from GBIF and NY were supplemented with herbarium specimen records from the three major Puerto Rican herbaria. The NY analysis identified 398 At Risk plant species, reduced from the 459 reported earlier (Miller et al., 2012), because of more adequate documentation of range and, therefore, greater EOO values resulting from the larger dataset and leading to fewer At Risk species. In the original NY analysis, it was not possible to calculate EOO for 142 species, which were known from fewer than three specimens, but with the larger dataset, it was possible to calculate EOO for all but 106 species, and the larger EOO values reduced the At Risk species by 62 . The US analysis recognized 359 At Risk species, based on the original dataset (Miller et al., 2012). In total, 510 species were considered At Risk in one or the other analyses, and 247 of these were identified as such in both.

The results of the expert analysis to provisionally assign all species to the IUCN Red List categories are summarized in a table available on NY's website (<http://sweetgum.nybg.org/caribbean/J_Miller_et_ al_Puerto_Rican_plant_conservation_status.pdf $>$ ). Species were considered Threatened when their calculated EOO was less than the $20,000 \mathrm{~km}^{2}$ threshold for $\mathrm{VU}$, and when experts' observations confirmed fragmented populations and likely de-
Table 1. Results of conservation analyses of Puerto Rican seed plants, contrasting provisional Red List category assignments with identification of species At Risk in the two streamlined conservation assessment methods. Provisional IUCN assignments were made by a local panel of experts. CR $=$ Critically Endangered; $\mathrm{EN}=$ Endangered; $\mathrm{VU}=$ Vulnerable.

\begin{tabular}{lccc}
\hline \hline $\begin{array}{c}\text { Provisional IUCN } \\
\text { assignments }\end{array}$ & $\begin{array}{c}\text { Streamlined } \\
\text { assessment } \\
\text { assignments }\end{array}$ & & \\
\hline NY method & US method & & \\
CR & 72 & $72(100 \%)$ & $72(100 \%)$ \\
EN & 97 & $96(99 \%)$ & $91(94 \%)$ \\
VU & 86 & $82(95 \%)$ & $53(62 \%)$ \\
Total (Threatened) & 255 & $250(98 \%)$ & $216(85 \%)$ \\
\hline
\end{tabular}

cline in known populations or available habitat. The analysis identified 72 species as CR, 97 species as EN, and 86 species as VU, for a total of 255 Threatened species. In addition, 44 more species were identified as Near Threatened (NT), and 1710 species were considered Least Concern (LC). The two streamlined conservation analyses both proved very effective at predicting which species were considered Threatened by more detailed IUCN Red List analyses (Table 1). Both predicted all 72 species considered to be CR, the NY analysis predicted $96(99 \%)$ and the US analysis 91 (94\%) of 97 EN species, and the NY analysis predicted 82 (95\%) and the US analysis $53(62 \%)$ of $86 \mathrm{VU}$ species. In total, the NY analysis predicted 250 (98\%) and the US analysis 216 (85\%) of 255 Threatened species, but the difference among the methods was not quite significant (chi square $=$ 4.32, $d f=2, P=0.12$ ). The NY analysis considered 148 more species At Risk, or $58 \%$ more than were not considered Threatened in the provisional IUCN listing. The US analysis identified 143 more species, or $56 \%$ more than were actually Red Listed. The three methods (the panel's assessment and the US and NY rapid assessment methods) did not differ significantly in the number of species assigned to the three categories (chi square $=5.71$, $d f=4, P=0.22$ ).

While each of the analyses was effective at identifying plants that would be considered Threatened by IUCN, they were even more effective when combined. The two analyses together identified all $169 \mathrm{CR}$ and EN species and 83 of 86 species that IUCN would consider VU. In total, the combined analyses identified $99 \%$ of the species IUCN would consider Threatened. There were 258 species identified as At Risk in one or the other analyses that were not considered Threatened in the Red List 
assignments, though 38 were among 44 species considered NT in the provisional Red List.

\section{Discussion}

It is clear that only a small percentage of the world's plant species have had their conservation status evaluated and that a streamlined, efficient process would help produce assessments in a timely manner that is responsive to the immediate threat that many species face. This study aimed to evaluate two methods that efficiently assess conservation status and used the flora of Puerto Rico as a test case.

Validation of the results of the two streamlined methods requires an assessment conducted by a method proven to produce credible results, against which the streamlined results can be compared. The panel of experts on the flora of Puerto Rico assembled at the University of Puerto Rico Botanical Garden in August 2011 used the IUCN guidelines (IUCN, 2001) to assess conservation status of all species potentially considered to be of conservation concern, under IUCN's criterion B. Geographic range has been considered a valid measure of conservation status in many previous studies (e.g., Gaston \& Fuller, 2009) and is one of the five measures that IUCN accepts for Red List assignments (IUCN, 2001). The expert review assigned $12.7 \%$ of the flora to one of the three Threatened categories, which is less than the $20 \%$ or more estimated for most tropical floras (Pitman \& Jorgensen, 2002; Brummitt et al., 2008), but quite similar to the $13.6 \%$ of the Puerto Rican flora considered to be endemic (Acevedo-Rodríguez \& Strong, 2007). It is likely that the results of this analysis are conservative in the sense that they identify only those species for which restricted geographic ranges clearly document evident conservation concern, and in this analysis, 44 additional species were considered NT.

Comparison of the results from the two streamlined methods with the provisional Red List indicates that they were both excellent predictors of conservation concern, with the NY analysis identifying $250(98 \%)$ of 255 Red List Threatened species and the US analysis identifying 216 (85\%) of 255 Threatened species. The NY analysis identified an additional 148 species (58\%) and the US analysis 143 species (56\%) as At Risk, beyond those considered Threatened in the Red List analysis. No further analysis of the geographic ranges of these additional species were completed, but review of the information included in this analysis supports the assumption that the vast majority of species considered At Risk but not Threatened are species with restricted ranges and that are hence of some conservation concern. In fact,
44 of the additional species were considered NT in the Red List analysis.

The two methods did yield somewhat different results. The NY method predicted $98 \%$ of the Red List Threatened species as compared with only $85 \%$ by the US method. Given that the two methods evaluated here both use readily available data and can be completed efficiently, they can be a realistic approach to identifying the list of species needed to satisfy Target 2 of the GSPC, the same group of species that most desperately need conservation to ensure their near-term survival.

\section{Conclusions}

The most widely used system for assessing conservation status, the IUCN or IUCN's Red List system, has made only limited progress reviewing the conservation status of plants, providing assessments for fewer than 15,000 species, or only about $4 \%$ of the estimated seed plant species. Given this progress, it seems unlikely that the 2020 deadline for Target 2 of the GSPC, a list of the world's endangered plants, will be met. A streamlined system that can expedite review of the conservation status of individual species, using readily available data, is needed to rapidly compile the list of species that merits conservation attention. The two systems reviewed here, to assess the validity of the conservation assessments that they produce, are intended to provide the means to rapidly evaluate large numbers of plant species and achieve Target 2 of the GSPC. Used either individually or in tandem, these systems provide an efficient approximation of and a first step toward a Red List and could facilitate assessments rather than being an alternative system that would replace the Red List.

The congruence between the NY analysis and the provisional Red List assessments from the expert panel was very good, with the NY list of At Risk species including all but five, or $98 \%$, of the species "Red Listed" as Threatened. The US analysis was not quite as effective, identifying only $85 \%$ of the Red Listed Species, 216 of 255 . The provisional Red List was conservative in recognizing Threatened species, and both analyses identified significantly more At Risk species, 148 additional in the NY and 143 more in the US analyses. Given that the provisional Red List also included 44 NT species, and that most of the At Risk species are range restricted even if not sufficiently so to be considered Threatened in the Red List, the results of both analyses are very efficient at identifying Threatened species and the additional species they identify are almost certainly worthy of some conservation concern. 
The two analyses combined were even more effective at identifying the Threatened species.

Given the efficiency at which the two tested methods evaluated the flora of Puerto Rico, using data that are readily available in internet-accessible databases, these methods could be very effective in evaluating the large numbers of species that will be necessary to reach Target 2 of the GSPC. Both methods require only a reliable checklist of the native plant species from the region to be evaluated (evaluations could also be organized taxonomically) and access to available herbarium specimen locality data. With the recent publication of checklists for Venezuela and Brazil (Hokche et al., 2008; < http:// floradobrasil.jbrj.gov.br/2010/>) and pending checklists for Bolivia and Colombia (Jorgensen, in prep.; Bernal, in prep.), the only part of the New World not likely to have the necessary data available in the near future would be Mexico.

The two efficient analyses tested here both provide a means of realistically working to complete the assessments required to attain Target 2 of the GSPC. Furthermore, the list of species that they would generate would almost certainly contain nearly all of the species that would be identified as Threatened in a comprehensive Red List analysis, as well as a modest percentage of species that are range restricted, though not sufficiently to be considered Threatened. This list would be a decisive positive step toward completing a much greater number of Red List assessments, because it first essentially Green Lists a large percentage of species that IUCN would consider LC, and then allows labor for more complete analyses to be focused on the species that might possibly be of conservation concern. Furthermore, completing the analyses via the NY method focuses the most laborintensive work, namely georeferencing those specimen records with locality data lacking geographic coordinates, on those species whose conservation status might actually be affected by redefinition of their geographic range. It is clear that some more efficient method will be required to achieve Target 2 of the GSPC, and the two methods presented here could both play a significant role in achieving that goal.

\section{Literature Cited}

Acevedo-Rodríguez, P. \& M. T. Strong. 2007. Catalogue of the seed plants of the West Indies Website. <http:// botany.si.edu/Antilles/WestIndies/catalog.htm>, accessed 12 July 2013.

Acevedo-Rodríguez, P. \& M. T. Strong. 2008. Floristic richness and affinities in the West Indies. Bot. Rev. 74: $5-36$.
Beyer, H. L. 2007. Hawth's analysis tools for ArcGIS, Version 3.27. <http://www.spatialecology.com/htools>, accessed 6 July 2012.

BirdLife International. 2008. State of the world's birds: Indicators for our changing world. BirdLife International, Cambridge. <http://www.birdlife.org/datazone/userfiles/ docs/SOWB2008_en.pdf $>$, accessed 12 July 2013.

BirdLife International. 2013. State of the world's birds: Indicators for our changing world. BirdLife International, Cambridge. <http://www.birdlife.org/datazone/ sowb/SOWB2013>, accessed 12 July 2013.

Bramwell, D. 2002. How many plant species are there? Pl. Talk 28: 32-34.

Brummitt N., S. P. Bachman \& J. Moat. 2008. Applications of the IUCN Red List: Towards a global barometer for plant diversity. Endangered Species Res. 6: 127-135.

Convention on Biological Diversity (CBD). 2002. Decision VI/9, Global Strategy for Plant Conservation, 2002-2010. Sixth Ordinary Meeting of the Conference of the Parties to the Convention on Biological Diversity (COP 6). The Hague, The Netherlands. <http://www.cbd.int/decision/ cop/?id=7183 $>$, accessed 12 July 2013.

Convention on Biological Diversity (CBD). 2010. Global Strategy for Plant Conservation: Technical Rationale, Justification for Updating and Suggested Milestones and Indicators. (UNEP/CBD/COP 10/19). Conference of the Parties to the Convention on Biological Diversity, Nagoya, Japan, 18-29 October 2010. <www.cbd.int/doc/meetings/ cop/cop-10/official/cop-10-19-en.doc $>$, accessed 12 July 2013.

Convention on Biological Diversity (CBD). 2011. Report of the Fourth Meeting of the Liaison Group on the Global Strategy for Plant Conservation. St. Louis, Missouri, 8-9 July 2011. UNEP/CBD/LG-GSPC/4/2. < http://www.cbd. $\mathrm{int} / \mathrm{doc} / \mathrm{meetings} / \mathrm{pc} / \mathrm{gspclg}$-04/official/gspclg-04-02-en. pdf $>$, accessed 12 July 2013.

Donaldson, J. 2003. Cycads. Status Survey and Conservation Action Plan. IUCN/SSC Cycad Specialist Group. IUCN, Gland, Switzerland, and Cambridge, United Kingdom.

ESRI. 2007. ArcGIS, Version 9.2. Environmental Systems Research Institute (ESRI), Redlands, California.

Farjon, A., S. Bachman, M. F. Gardner, D. Luscombe, C. Reynolds \& P. Thomas. 2006. Conservation Assessments of Data Deficient (DD) Conifers, Using Herbarium and Geographical Information System (GIS) Data. Royal Botanic Gardens, Kew, Edinburgh.

Gaston, K. J. \& R. A. Fuller. 2009. The sizes of species geographic ranges. J. Appl. Ecol. 46: 1-9.

Govaerts, R. 2001. How many species of seed plants are there? Taxon 50: 1085-1090.

Hokche, O., P. E. Berry \& O. Huber. 2008. Nuevo Catálogo de la Flora Vascular de Venezuela. Fundación Instituto Botánico de Venezuela Dr. Tobias Lasser, Caracas.

IUCN. 2001. IUCN Red List Categories and Criteria, Version 3.1. Prepared by the IUCN Species Survival Commission. IUCN, Gland, Switzerland, and Cambridge, United Kingdom.

IUCN. 2008. Guidelines for using the IUCN Red List Categories and Criteria, Version 7.0. Prepared by the IUCN Species Survival Commission. IUCN, Gland, Switzerland, and Cambridge, United Kingdom.

IUCN. 2009. The IUCN Red List of Threatened Species 2009 update: Plant Facts. IUCN, Gland, Switzerland, and Cambridge, United Kingdom. [<http://cmsdata.iucn.org/ downloads $>$ ]. 
IUCN. 2011. IUCN Red List of Threatened Species, Version 2011.1. IUCN, Gland, Switzerland, and Cambridge, United Kingdom. <https://www.iucnredlist.org >, accessed 12 July 2013.

Joppa, L. N., D. L. Roberts \& S. L. Pimm. 2010. How many species of flowering plants are there? Proceedings of the Royal Society Biology. <http://www.ncbi.nlm.nih.gov/ pmc/articles/PMC3025670/>, published online 7 July 2010. In print, 2011. Proc. Biol. Sci. 278 (1705): 554559.

Krupnick, G. A., W. J. Kress \& W. L. Wagner. 2009. Achieving Target 2 of the Global Strategy for Plant Conservation: Building a preliminary assessment of vascular plant species using data from herbarium specimens. Biodivers. Conserv. 18: 1459-1474.

Miller, J. S. 2011. Nature's potential: How many drugs could come from plants? Pp. 125-140 in B. E. Ponman \& J. S. Miller (editors), Realizing Nature's Potential, Proceedings of the William L. Brown Symposium Honoring Dr. Gordon Cragg. Monogr. Syst. Bot. Missouri Bot. Gard. 118.

Miller, J. S., H. A. Porter-Morgan, G. A. Krupnick, P. Acevedo-Rodríguez, H. Stevens, J. Fleming \& M. Gensler. 2012. Addressing Target Two of the Global Strategy for Plant Conservation by rapidly identifying plants at risk. Biodivers. Conserv. 20 (1). <http://www. nybg.org/files/puerto_rico_conservation.pdf $>$, accessed 12 July 2013.

NatureServe. 2013. NatureServe Explorer: An online encyclopedia of life [web application], Version 7.1. NatureServe, Arlington, Virginia. <http://www.natureserve.org/ explorer/>, accessed 12 July 2013.

Pitman, N. C. A. \& P. M. Jorgensen. 2002. Estimating the size of the world's threatened flora. Science 298: 989.

Prance, G. T., H. Beentje, J. Dransfield \& R. Johns. 2000. The tropical flora remains undercollected. Ann. Missouri Bot. Gard. 87: 67-71.

Puerto Rican Endangered Plants Initiative. 2012. <http:// sweetgum.nybg.org/caribbean/prepi.php $>$, accessed 12 July 2013.

Schipper, J., J. Chanson, F. Chiozza, N. Cox, M. Hoffmann, V. Katariya, J. Lamoreux, A. S. L. Rodrigues, S. N. Stuart, H. J. Temple, J. E. M. Baillie, L. Boitani, T. E. Lacher, R. A. Mittermeier, A. T. Smith, D. Absolon, J. M. Aguiar, G. Amori, N. Bakkour, R. A. Baldi, R. J. Berridge, J. Bielby, P. A. Black, J. J. Blanc, T. M. Brooks, J. A. Burton, T. M. Butynski, G. Catullo, R. Chapman, Z. Cokeliss, B. Collen, J. Conroy, J. G. Cooke, G. A. B. da Fonseca, A. E. Derocher, H. T. Dublin, J. W.
Duckworth, L. Emmons, R. H. Emslie, M. FestaBianchet, M. Foster, S. N. Foster, D. L. Garshelis, C. Gates, M. Gimenez-Dixon, M. Gonzalez, J. F. GonzalezMaya, T. C. Good, G. Hammerson, P. S. Hammond, D. Happold, M. Happold, J. Hare, R. B. Harris, C. E. Hawkins, M. Haywood, L. Heaney, S. Hedges, K. M. Helgen, C. Hilton-Taylor, S. A. Hussain, N. Ishii, T. A. Jefferson, R. K. B. Jenkins, C. H. Johnston, M. Keith, J. Kingdon, D. Knox, J. M. Kovacs, P. Langhammer, K. M. Leus, R. Lewison, G. Lichtenstein, L. F. Lowry, Z. Macavoy, G. M. Mace, D. P. Mallon, M. Masi, M. W. McKnight, R. Medellín, P. Medici, G. Mills, P. D. Moehlman, S. Molur, A. E. Mora, K. Nowell, J. F. Oates, W. Olech, W. L. R. Oliver, M. Oprea, B. Patterson, W. F. Perrin, B. A. Polidoro, C. Pollock, A. Powel, Y. Protas, P. A. Racey, J. Ragle, P. Ramani, G. Rathbun, R. R. Reeves, S. B. Reilly, J. E. Reynolds III, C. Rondinini, M. Rulli, A. B. Rylands, S. Savini, C. J. Schank, W. Sechrest, C. Self-Sullivan, A. Shoemaker, C. SilleroZubiri, N. Silva, D. E. Smith, C. Srinivasulu, P. J. Stephenson, N. van Strien, B. K. Talukdar, B. L. Taylor, R. Timmins, D. G. Tirira, M. F. Tognelli, K. Tsytsulina, L. M. Veiga, J.-C. Vié, L. Williamson, S. A. Wyatt, Y. Xie \& B. E. Young. 2008. The status of the world's land and marine mammals: Diversity, threat and knowledge. Science 322: 225-230. <http://www.sciencemag.org/ content/322/5899/225>, accessed 12 July 2013.

SEMARNAT (Secretaría de Medio Ambiente y Recursos Naturales). 2002. Norma Oficial Mexicana NOM-059ECOL-2001, protección ambiental-especies nativas de México de flora y fauna silvestres-categorías de riesgo y especificaciones para su inclusíon, exclusión o cambiolista de especies en riesgo. Diario Oficial de la Federación (6 de marzo de 2002), Primera sección. Diario Oficial de la Federación, Mexico City.

Stebbins, G. L. 1974. Flowering Plants: Evolution beyond the Species Level. The Belknap Press of Harvard University, Cambridge.

Stuart, S. N., M. Hoffmann, J. S. Chanson, N. A. Cox, R. J. Berridge, P. Ramani \& B. E. Young. 2008. Threatened Amphibians of the World. Lynx Edicions, Barcelona; IUCN, Gland, Switzerland; and Conservation International, Arlington, Virginia. <http://www.iucnredlist.org/ initiatives/amphibians/process/publications $>$, accessed 12 July 2013.

Willis, F., J. Moat \& A. Paton. 2003. Defining a role for herbarium data in Red List assessments: A case study of Plectranthus from Eastern and Southern tropical Africa. Biodivers. Conserv. 12: 1537-1552. 